\title{
PEMANFAATAN PANAS DI PIPA TEKANAN TINGGI PADA MESIN PENDINGIN (AC)
}

\author{
Candra Yusfi Amri Aziz ${ }^{1}$, Rahmat Firdaus ${ }^{2}$ \\ 1,2Prodi Teknik Mesin Fakultas Teknik Universitas Muhammadiyah Sidoarjo \\ JI.Raya Gelam 250 Candi Sidoarjo \\ Email: candrayusfiamriaziz@gmail.com
}

\begin{abstract}
The purpose of this research is to know the design of AC cooling machine system by using water cooling media in condenser, to know the influence of cooling water media on condenser to cooling machine performance ( $A C)$, to know COP cooling capacity based on the addition of water cooling media in condenser. The experiment was conducted by experimental method, which was used to test the temperature variation by analyzing air temperature (Th), water temperature (TC), suction and discharge pressure, condenser inlet and outlet temperature, COP and cooling machine efficiency performed every 5 minutes once. The results showed, maximum temperature that can be achieved of cooling machine system is $\left(4.4^{\circ} \mathrm{C}\right)$ at minute 10 for cooling machine with air fan cooling medium $\left(-6,9^{\circ} \mathrm{C}\right)$ at minute 15 For cooling machine with water cooling medium $\left(-12,7^{\circ} \mathrm{C}\right)$ at minute 15 for cooling machine with water cooling medium and air fan. The flowing water flow affects the achievement of the best temperature and efficiency. In this experiment, the result of the mass of water flowing every minute is $0,4603 \mathrm{~kg} / \mathrm{s}$ and able to stabilize hot calor to reach temperature $\left(32^{\circ} \mathrm{C}\right)$ which can be used for other needs.
\end{abstract}

Keywords: Coefficient Of Performance, Cooling Machine, Water Rate, Temperature, Pressure.

\section{PENDAHULUAN}

Saat ini teknologi mesin pendingin $P$ sangatlah berpengaruh bagi kehidupan modern, tidak hanya terbatas dalam peningkatan kualitas dan kenyamanan hidup tetapi juga mencakup hal-hal esensial dalam kehidupan manusia. Air Conditioner $(A C)$ merupakan sebuah alat yang sengaja dirancang agar memiliki fungsi untuk mengondisikan temperatur udara. Air Conditioner (AC) bisa juga dikatakan sebagai alat yang berfungsi untuk penyejuk atau pendingin udara. Menggunakan Air Conditioner (AC) diharapkan mendapatkan temperatur udara yang diinginkan dan memberi rasa nyaman bagi pengguna didalam ruangan, seperti: pusat perbelanjaan modern, perkantoran, transportasi, rumah dan juga ruangan lainnya yang menggunakan alat pendingin tersebut [1].

Air Conditioner (AC) tidak saja membuat udara menjadi lebih dingin akan tetapi juga bisa meningkatkan kualitas udara dan bisa mengurangi gejala penyakit asma dan alergi. Di wilayah yang beriklim tropis seperti di Indonesia dengan kondisi temperatur udara yang relatif panas banyak orang menggunakan alat pendingin ini. Pengondisi udara (AC) tergolong barang mewah dikarenakan harganya yang cukup mahal dan daya listrik yang dibutuhkan juga cukup besar.

Dalam penelitian [2] telah mendapatkan hasil perhitungan untuk kebutuhan AC yang di aplikasikan terhadap suatu ruangan dengan di tentukan oleh luas ruangan dan koefisien mesin pendingin, dimana koefisien $1 \mathrm{~m} 2=500 \mathrm{BTU} / \mathrm{hr}$ untuk standar ruangan dengan ketinggian 2,5 $3,3 \mathrm{~m}$. Misalkan dengan ruangan yang berukuran $3 \mathrm{~m} \times 4 \mathrm{~m}$ kebutuhan AC nya adalah $3 \mathrm{~m} \times 4 \mathrm{~m}$ dengan koefisien $500 \mathrm{BTU} / \mathrm{hr}$ didapatkan hasil $6000 \mathrm{BTU} / \mathrm{hr}$ yang artinya kebutuhan AC untuk ruangan $3 \mathrm{~m} \times 4 \mathrm{~m}=6000 \mathrm{BTU} / \mathrm{hr}$ dengan kompresor $\mathrm{AC}$ bisa menghasilkan antara $8.000-$ $10.000 \mathrm{BTU} / \mathrm{hr}$. Bila hitungan $=6000 \mathrm{BTU} / \mathrm{hr}$ setara dengan 0,6667 PK maka disarankan untuk menggunakan AC yang memiliki kapasitas 0,75 $\mathrm{PK}=3 / 4 \mathrm{PK}=7.000 \mathrm{BTU} / \mathrm{hr}$ karena sudah 
memenuhi kebutuhan ruangan dengan luas $3 \mathrm{~m} \times$ $4 \mathrm{~m}$.

Namun, bagi kebanyakan orang alat pendingin ini sudah tidak termasuk barang mewah lagi karena melihat manfaatnya untuk mengatur temperatur dan siklus udara yang memberikan efek pada kenyamanan tubuh pengguna. Tidak hanya itu saja, AC juga dapat mengatur kebersihan udara dan kelembapan udara didalam suatu ruangan sehingga akan tercipta kondisi udara yang berkualitas dan sehat. Terlebih lagi bagi perkantoran dan dunia industri tingkat kenyaman yang diperoleh dari suatu pendingin dan pengkondisian udara akan begitu terasa manfaatnya untuk kehidupan sehari-hari.

Agar bisa membuat temperatur yang nyaman dan sejuk didalam ruangan sesuai yang diinginkan, semaksimal mungkin temperatur suhu udara dalam ruangan diatur dan dikondisikan sesuai dengan kebutuhan terlebih dahulu. Proses pendinginan atau penurunan temperatur udara perlu dilakukan ketika temperatur udara didalam dan luar ruangan tinggi (panas). Sebaliknya, apabila memanaskan atau menaikkan temperatur udara dilakukan ketika temperatur didalam dan diluar ruangan. Sangat rendah (dingin), seperti halnya kondisi bersalju di daerahdaerah yang mempunyai empat musim.

Pada setiap unit AC akan dilengkapi dengan filter udara yang terpasang pada bagian evaporator (indoor). Dengan begitu filter tersebut berfungsi sebagai penyaring udara kotor didalam ruangan tersebut. Oleh sebab itu unit AC membutuhkan pembersihan secara berkala dengan benar dan baik pada komponen filter atau evaporatornya. Hal tersebut diperlukan untuk kesejukan dan kebersihan udara didalam suatu ruangan agar tetap terjaga dan tidak akan menimbulkan resiko yang buruk bagi kesehatan para penggunanya.

Namun pada sebuah mesin pendingin AC juga memilki sebuah kekurangan yakni salah satunya adalah perawatan yang memiliki jangka waktu pendek dan membuat biaya perawatan semakin bertambah, disebabkan karena terlalu panasnya alat-alat mesin pendingin yang mengakibatkan kerak dan menjadikan umur alat jauh lebih pendek sehingga efisiensi menjadi berkurang. Maka dari itu dalam penelitian ini akan mencoba membuat eksperimen apakah media air dapat menjadi solusi pengganti alat penukar panas yang biasanya di pergunakan udara untuk mendinginkan refrigeran di dalam sistem pendingin. Dan seperti mana kita tahu air merupakan media pendingin yang lebih bagus dari pada udara.

Chiller merupakan sebuah mesin refrigerasi yang memiliki fungsi mendinginkan refrigeran pada sisi evaporatornya. Air dingin yang dihasilkan langsung didistribusikan ke dalam alat penukar kalor yakni Fan Coil Unit (FCU). Sistem water chiller memiliki dua siklus yakni siklus primer dan siklus sekunder. Dalam siklus primer yang bertugas sebagaii fluida kerja adalah refrigeran, dan pada siklus sekunder yang bertindak sebagai fluida kerja adalah air. Prinsip kerjanya adalah air disirkulasikan oleh pompa yang dapat diatur laju alirannya dengan bantuan flowmeter. Sangatlah penting untuk mengatur laju volume media air pendingin untuk mendapatkan sebuah pendinginan yang maksimal, air pendingin tersebut nanti berfungsi mengambil panas ruangan [3].

Dengan laju aliran yang sangat tinggi akan didapatkan pendinginan ruangan yang cepat, dikarenakan kecepatan tinggi dapat mempengaruhi fluida pendingin untuk menukar panas ruang. Selain itu agar mengetahui laju aliran volume yang paling sesuai untuk sebuah sistem Mini Chiller untuk memperoleh perpindahan panas yang lebih maksimal dapat dilakukan dengan menganalisa Number Transfer Unit (NTU).

Number Transfer Unit (NTU) yakni parameter yang tidak memiliki dimensi dan dipergunakan untuk menganalisa perpindahan kalor pada suatu alat penukar panas. Tolak ukur dalam penelitian ini adalah bahwa dengan NTU yang semakin besar akan mendapatkan laju perpindahan panas yang besar dari suatu alat penukar panas.

Air sangatlah penting untuk proses produksi ataupun kegiatan lain dalam suatu industri atau lingkungan. Air sebagai media pendingin sangatlah diperlukan dalam proses perindustrian. Kualitas air pendingin akan dapat mempengaruhi dalam integritas komponen dan struktur material, karena langsung mengalami kontak dan berhubungan secara langsung [4]. Overheating (panas yang berlebihan) pada suatu mesin sangat berpengaruh terhadap kestabilan kinerja mesin tersebut. Oleh karena itu dalam 
penelitian ini akan menggunakan media air untuk membantu proses pendinginan agar dapat mengontrol sistem temperatur dan tekanan dengan cara memindahkan kalor dari fluida dan mengeluarkannya ke lingkungan sekitar.

Media pendingin air memiliki pengaruh besar terhadap efisiensi dan umur suatu mesin. Apabila temperatur yang masuk ke dalam sistem terlalu tinggi dan dibiarkan berangsur-angsur maka otomatis efisiensi mekanis sebuah mesin akan menurun dan dapat menyebabkan overheating.

Adapun beberapa keunggulan air jika digunakan sebagai media pendingin pada mesin pendingin (AC) yaitu, sangat berlimpah dan mudah didapatkan, dapat ditangani dengan mudah dan aman untuk digunakan, dapat membawa kalor per unit volume dalam jumlah yang besar, air tidak mudah mengembang ataupun menyusut (volumenya) terhadap perubahan suhu dalam batasan dengan adanya perubahan temperatur pendingin.

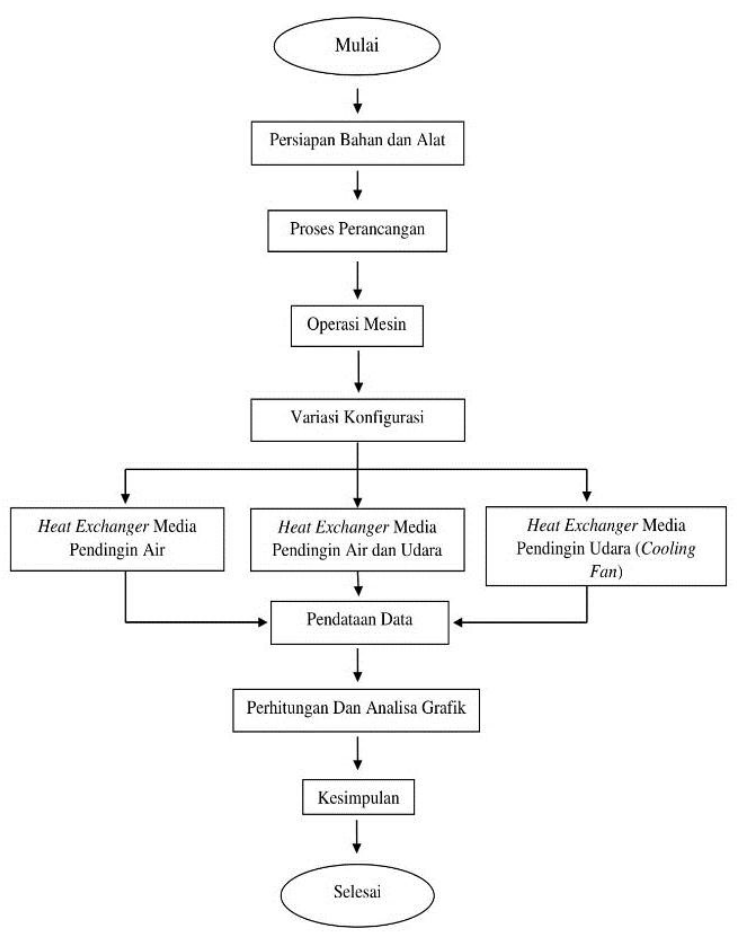

Gambar 1. Flowchart

\section{METODE PENELITIAN}

Metode penelitian yang digunakan dalam penelitian ini adalah metode eksperimental. dengan melakukan pengujian langsung pada prototype Mini Chiller.

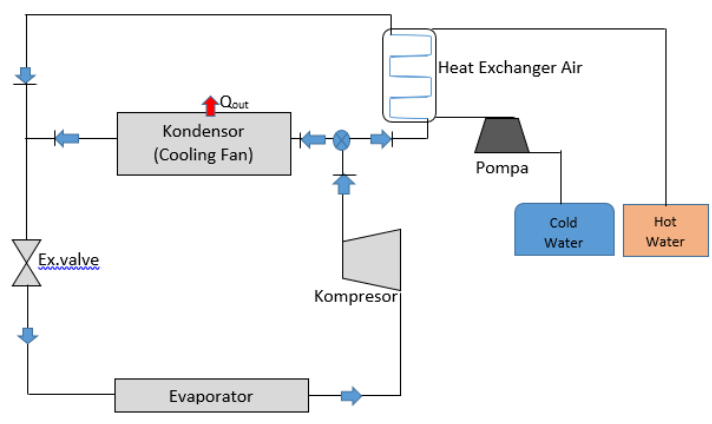

Gambar 2. Miniatur Water Chiller

Mini Chiller ini sebenarnya merupakan $A C$ split yang dimodifikasi menjadi water Chiller. Berikut ini metode penelitiannya:

a. Persiapan Percobaan

Instalasi telah disiapkan untuk melaksanakan percobaan dan pengambilan data.

b. Menjalankan Instalasi

1. Saklar dipasang pada posisi (ON)

2. Regavolt diatur supaya ada aliran udara melalui evaporator dengan tujuan membebani evaporator dengan mengatur posisi regavolt sesuai varian data untuk masing-masing kelompok.

3. Kompresor dijalankan sehingga terjadi siklus refrigeran. Instalasi dibiarkan beropersi sampai terbentuk air kondensasi pada evaporator dan ditampung pada gelas ukur yang sudah dipasang termometer.

4. Pemvariasian konfigurasi penggunaan bukaan valve untuk mengatur media pendinginan dalam sistem pendingin menggunakan heat exchanger air saja, media pendinginan dalam sistem pendingin menggunakan heat exchanger udara dari cooling fan saja, ataupun dengan menggunakan heat exchanger air dan kondensor udara secara bersamaan.

c. Menghentikan Operasi

1. Semua saklar dari semua komponen pelengkap dimatikan 
2. Kompresor dimatikan

3. Regavolt diturunkan posisinya secara perlahan sampai posisi " 0 "

4. Matikan saklar induk

5. Cabut steker dan power supply

\section{Pengambilan Data}

a. Data yang diambil adalah temperatur pada setiap termometer; temperatur refrigeran masuk dan keluar evaporator serta kondensor; tekanan refrigeran keluar evaporator dan kondensor; tekanan pada Inclined manometer; temperatur kondensasi; debit air masuk dan debit air kondensasi yang terpasang pada $A C$.

b. Pengambilan data baru boleh dimulai setelah ada air kondensat yang terbentuk pada evaporator (terlihat pada jatuhnya tetes air pada gelas ukur penampung air kondensat).

c. Setiap kombinasi parameter diambil data selama 60 menit dan diambil dat tiap 5 menit sekali.

d. Data-data dianggap valid jika pencatatan dilakukan setelah kondisi betul-betul dalam keadaan steady.

e. Data temperatur awal air adalah $27^{\circ} \mathrm{C}$ yang akan dialirkan dari pipa untuk membantu mendinginkan pipa tembaga refrigerant sebelum masuk ke dalam kondensor fan udara. Data tekanan suction dan discharge diperlukan untuk mengetahui kinerja sistem pendingin yang berhubungan dengan kinerja refrigerant yang bersirkulasi didalam siklus tersebut. Tekanan suction dan discharge tergantung dari jenis refrigerant yang dipakai, pada penelitian kali ini refrigerant yang digunakan adalah R-22. Data temperatur pada ekspansi dan suction diperlukan untuk menganalisa kinerja performansi sistem mesin pendingin.

f. Berdasarkan siklus refrigerant yang tergantung didalamnya maka data-data yang didapatkan akan disajikan dala tabel 1,2, dan tabel 3 dibawah ini:
Tabel 1. Data Miniatur Mesin Pendingin Dengan Media Pendingin Fan Udara

\begin{tabular}{|c|c|c|c|c|c|c|c|c|c|}
\hline \multirow[b]{2}{*}{ Minute } & \multicolumn{2}{|c|}{ Temperature $\left({ }^{\circ} \mathrm{C}\right)$} & \multicolumn{2}{|c|}{ Pressure Gauge (Br) } & \multicolumn{3}{|c|}{ Temperature $\left({ }^{\circ} \mathrm{C}\right)$} & \multirow[b]{2}{*}{ COP } & \multirow[b]{2}{*}{ Effíciency } \\
\hline & $\begin{array}{l}\text { Uddras } \\
\text { (Th1) }\end{array}$ & $\begin{array}{l}\text { Uddras } \\
(\mathrm{th} 0)\end{array}$ & Discharge & Suction & $\begin{array}{l}\text { Discharge } \\
\text { Condenser }\end{array}$ & $\begin{array}{c}\text { Suction } \\
\text { Condenser }\end{array}$ & $\begin{array}{c}\text { Out } \\
\text { Evaporator }\end{array}$ & & \\
\hline 1 & 33 & 35 & 25,1 & 8,1 & 56 & 24,2 & 19,1 & 8,3 & $56 \%$ \\
\hline 5 & 32,5 & 35,4 & 25,5 & 8,6 & 60 & 8,9 & 19,6 & 11.5 & $37 \%$ \\
\hline 10 & 33 & 35,6 & 25,6 & 8,95 & 68 & 4,4 & 19,0 & 5,8 & $68 \%$ \\
\hline 15 & 33 & 35 & 25,6 & 9,2 & 72 & 5,4 & 18,5 & 5,5 & $80 \%$ \\
\hline 20 & 33,4 & 36 & 26,1 & 9,2 & 73 & 5,4 & 17,7 & 4,8 & $95 \%$ \\
\hline 25 & 33,1 & 35 & 26,2 & 9,2 & 74 & 5,7 & 18,0 & 4,8 & $97 \%$ \\
\hline 30 & 33 & 35 & 26,2 & 9,2 & 75 & 6,1 & 17,5 & 4,8 & $97 \%$ \\
\hline 35 & 33 & 35 & 26,2 & 9,25 & 77 & 6,5 & 18,3 & 4,3 & $97 \%$ \\
\hline 40 & 33 & 35,6 & 26,8 & 9,45 & 77 & 6,5 & 18,5 & 4,4 & $93 \%$ \\
\hline 45 & 3,7 & 35,5 & 26,5 & 9,45 & 77 & 6,8 & 18,2 & 4,4 & $93 \%$ \\
\hline 50 & 33,3 & 35 & 26,8 & 9,45 & 78 & 6,8 & 17,4 & 4,5 & $93 \%$ \\
\hline 55 & 33 & 35 & 26,8 & 9,45 & 78 & 6,9 & 17,9 & 4,8 & $94 \%$ \\
\hline 60 & 33 & 35 & 26,8 & 9,3 & 78 & 7,0 & 18,3 & 5,4 & $92 \%$ \\
\hline
\end{tabular}

Tabel 2. Data Miniatur Mesin Pendingin Dengan Media Pendingin Air

\begin{tabular}{|c|c|c|c|c|c|c|c|c|l|}
\hline \multirow{2}{*}{ Minute } & \multicolumn{2}{|c|}{ Temperature $\left({ }^{\circ} \mathrm{C}\right)$} & \multicolumn{2}{|c|}{ Pressure Gauge (Bar) } & \multicolumn{3}{|c|}{ Temperature $\left({ }^{\circ} \mathrm{C}\right)$} & \multirow{2}{*}{} \\
\cline { 2 - 8 } & Air (Th1) & Air (Tho) & Discharge & Suction & $\begin{array}{c}\text { Discharge } \\
\text { Condenser }\end{array}$ & $\begin{array}{c}\text { Suction } \\
\text { Condenser }\end{array}$ & $\begin{array}{c}\text { Out } \\
\text { Evaporator }\end{array}$ & \multirow{2}{*}{ COP } & Efficiency \\
\hline 1 & 26 & 28,3 & 20,1 & 3,2 & 54 & 26,6 & 18,5 & 5,3 & $52 \%$ \\
\hline 5 & 26,8 & 29,4 & 20,1 & 4,5 & 56 & 7,4 & 18,7 & 5,8 & $57 \%$ \\
\hline 10 & 27 & 29,5 & 20,1 & 4,5 & 58 & $-6,9$ & 19,1 & 6,6 & $45 \%$ \\
\hline 15 & 26,2 & 29,9 & 20,6 & 4,65 & 61 & $-3,8$ & 19,3 & 3,6 & $93 \%$ \\
\hline 20 & 26,4 & 30 & 21,5 & 4,55 & 64 & $-2,0$ & 19,1 & 3,8 & $85 \%$ \\
\hline 25 & 26 & 30,1 & 21,9 & 5,4 & 68 & $-1,1$ & 18,3 & 4,3 & $75 \%$ \\
\hline 30 & 27 & 31,1 & 22,8 & 5,4 & 72 & $-1,0$ & 18 & 3,3 & $95 \%$ \\
\hline 35 & 26,6 & 31,2 & 22 & 5,3 & 73 & $-2,3$ & 17,4 & 3,4 & $90 \%$ \\
\hline 40 & 27 & 31,5 & 21,8 & 5,4 & 77 & 0,3 & 17,6 & 3,1 & $89 \%$ \\
\hline 45 & 26 & 31,7 & 22,7 & 5,4 & 79 & 0,7 & 17,9 & 3,2 & $95 \%$ \\
\hline 50 & 26,2 & 32,9 & 22,7 & 5,9 & 81 & 0,3 & 18,2 & 3,5 & $90 \%$ \\
\hline 55 & 27 & 33 & 23,5 & 6,0 & 81 & 1,0 & 18 & 3,5 & $97 \%$ \\
\hline 60 & 26,8 & 33,7 & 23,5 & 6,0 & 81 & 1,5 & 18,1 & 3,5 & $97 \%$ \\
\hline
\end{tabular}

Tabel 3. Data Miniatur Mesin Pendingin Dengan Media Pendingin Air Dan Fan Udara

\begin{tabular}{|c|c|c|c|c|c|c|c|c|c|c|c|}
\hline \multirow[b]{2}{*}{ Minute } & \multicolumn{4}{|c|}{ Temperature $\left({ }^{\circ} \mathrm{C}\right)$} & \multicolumn{2}{|c|}{ Pressure Gauge (Bar) } & \multicolumn{3}{|c|}{ Temperatuse $\left({ }^{\circ} \mathrm{C}\right)$} & \multirow[b]{2}{*}{$\mathrm{COP}$} & \multirow[b]{2}{*}{ Efficiency } \\
\hline & $\begin{array}{l}\text { Udars } \\
\text { (Th1) }\end{array}$ & $\begin{array}{l}\text { Udara } \\
\text { (Tho) }\end{array}$ & $\begin{array}{c}\text { Air } \\
\text { (Th1) }\end{array}$ & $\begin{array}{c}\text { Air } \\
\text { (Tho) }\end{array}$ & Suction & Discharge & $\begin{array}{l}\text { Discharge } \\
\text { Condenser }\end{array}$ & $\begin{array}{c}\text { Suction } \\
\text { Condenser }\end{array}$ & \begin{tabular}{|c|c} 
Out \\
evaporat \\
of
\end{tabular} & & \\
\hline 1 & 31,8 & 34,2 & 26,2 & 28,5 & 20,3 & 4,75 & 53 & 22,8 & 18,2 & 6,7 & $49 \%$ \\
\hline 5 & 32 & 34 & 26 & 29 & 21 & 5,95 & 55 & 10,9 & 18 & 7,2 & $55 \%$ \\
\hline 10 & 32,5 & 33,9 & 26 & 29,4 & 21 & 5,95 & 62 & $-7,9$ & 18,7 & 4,7 & $73 \%$ \\
\hline 15 & 32,2 & 34,3 & 26,8 & 29,7 & 21 & 5,95 & 64 & $-12,7$ & 19,3 & 4,4 & $76 \%$ \\
\hline 20 & 31,9 & 34 & 27 & 29,9 & 21 & 6,0 & 69 & $-9,7$ & 18 & 4,0 & $92 \%$ \\
\hline 25 & 32 & 34 & 26,6 & 29,9 & 21 & 6,0 & 69 & $-9,5$ & 17,7 & 3,9 & $91 \%$ \\
\hline 30 & 32,1 & 34 & 26,4 & 30 & 21,8 & 6,0 & 72 & $-7,2$ & 17,3 & 3,4 & $97 \%$ \\
\hline 35 & 31,8 & 33,8 & 26,2 & 30,2 & 22,3 & 7,5 & 77 & $-6,9$ & 17,9 & 4,4 & $84 \%$ \\
\hline 40 & 31,9 & 34 & 26 & 30,6 & 22,7 & 7,45 & 77 & $-6,9$ & 18,2 & 4,5 & $93 \%$ \\
\hline 45 & 32,4 & 34,1 & 26,4 & 31 & 22,8 & 7,7 & 79 & $-8,4$ & 18,3 & 4,1 & $93 \%$ \\
\hline 50 & 32 & 34,2 & 26,1 & 31,6 & 22,8 & 7,7 & 83 & $-5,9$ & 19 & 3,9 & $91 \%$ \\
\hline 55 & 32,1 & 34 & 26 & 31,9 & 22,8 & 7,7 & 85 & $-6,3$ & 18,5 & 3,6 & $95 \%$ \\
\hline 60 & 31,9 & 34 & 26,3 & 32 & 23,4 & 7,9 & 85 & $-5,4$ & 18,2 & 3,4 & $98 \%$ \\
\hline
\end{tabular}


Perhitungan Massa Laju Air ma

$\dot{m}_{a}=\rho . v$

$\mathrm{Tc}=\frac{\mathrm{Tc} 1+\mathrm{Tc} 0}{2}$

$\mathrm{TC}=\frac{27+32}{2}$

$\mathrm{TC}=43^{\circ} \mathrm{C} \quad=1004,1 \mathrm{~kg} / \mathrm{m}^{3}$

Kapasitas pompa yang digunakan dalam penelitian ini adalah 25 liter.

1 liter $=0,0000917 \mathrm{~m}^{3} / \mathrm{s}$

$\dot{\mathrm{m}}_{\mathrm{a}}=\rho \cdot \mathrm{v}$

$\dot{\mathrm{m}}_{\mathrm{a}}=1004,1.0,0004585$

$\dot{\mathrm{m}}_{\mathrm{a}}=0,4603 \mathrm{~kg} / \mathrm{s}$

Jadi laju massa air yang mengalir adalah 0,4603 $\mathrm{kg} / \mathrm{s}$

\section{Analisa Perbandingan Temperatur Setelah Melewati Kondensor}

Dari grafik 4 dapat ditarik kesimpulan bahwa temperatur pipa tembaga setelah didinginkan kondensor terdapat lima variabel berbeda. Dalam penelitian ini variabel yang pertama adalah media pendingin fan udara saja yang setelah diuji titik awalnya berada di temperatur $24,2^{\circ} \mathrm{C}$, lalu pada menit ke-5 langsung turun pada titik $2,9^{\circ} \mathrm{C}$ dan perlahan mengalami kenaikan temperatur dengan stabil hingga menit ke-60 berada dititik $7^{\circ} \mathrm{C}$ dan suhu terendah yang dapat dicapai adalah $2,9^{\circ} \mathrm{C}$.

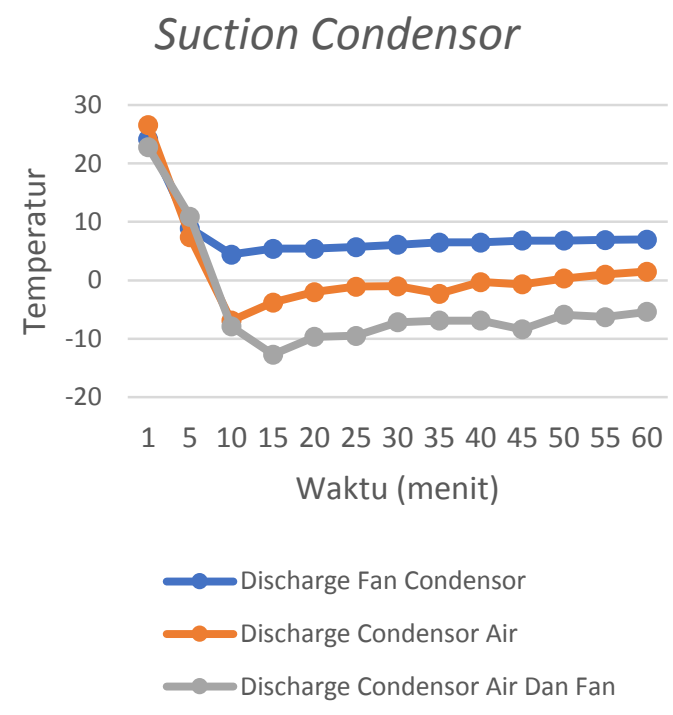

Gambar 4. Grafik Perbandingan Temperatur Setelah Melewati Kondensor
Untuk variabel kedua (kuning) adalah media pendingin air saja dengan menggunakan Freon normal yang setelah diuji titik awalnya berada di temperatur $26,6^{\circ} \mathrm{C}$, lalu pada menit ke5 langsung turun hingga $-7,9^{\circ} \mathrm{C}$ dan sempat mengalami naik turun hingga akhir nya pada menit ke-60 mencapai termperatur $1,5^{\circ} \mathrm{C}$ dan suhu terendah yang dapat tercapai adalah $7,9^{\circ} \mathrm{C}$. Temperatur berjalan naik dikarenakan adanya kerja kompresor yang lama kelamaan akan menjadikan pipa tembaga semakin panas dengan tekanan yang tinggi pula.

Variabel yang ke-3 (abu-abu) yaitu media pendingin air dan udara dengan menggunakan Freon normal yang setelah diuji titik awalnya berada di temperatur $22,8^{\circ} \mathrm{C}$, kemudian langsung turun pada menit ke-5 hingga $10,9^{\circ} \mathrm{C}$ dan perlahan turun hingga titik minus pada temperatur terendah $-12,7^{\circ} \mathrm{C}$ dan perlahan naik sampai $5,4^{\circ} \mathrm{C}$ pada menit akhir percobaan. Temperatur di kondensor konfigurasi ganda ini terbilang sangat efisien dan paling stabil diantara yang lainnya. Kondensor ganda ini mampu mencapai titik minus dan mempertahankan temperatur sehingga kinerja sistem mesin pendingin berjalan optimal dan maksimal kinerjanya.

\section{Analisa COP Dan Efisiensi}

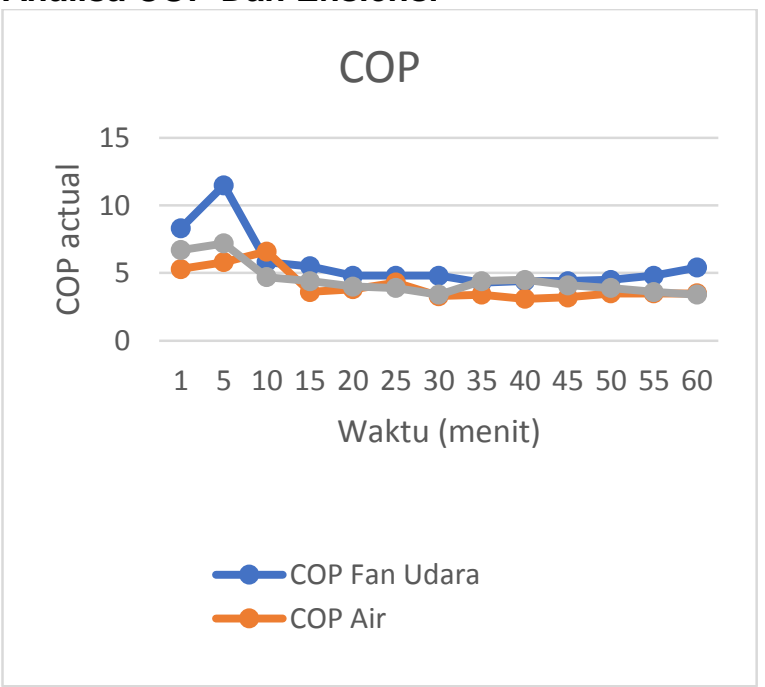

Gambar 5. Grafik Perbandingan COP actual

Dari grafik diatas dapat kita simpulkan koefisien performansi dari mesin pendingin bahwa COP aktual lebih rendah dibandingkan 
dengan COP carnot, seperti telah ditulis pada tinjauan pustaka bahwa kondisi yang akan dicapai oleh sistem refrigerasi kompresi uap ideal adalah jumlah energi yang masuk sama dengan energi yang diperlukan untuk melakukan kerja ditentukan oleh $\mathrm{COP}=1$. Kenyataannya efek refrigerasi selalu lebih besar dari pada kerja kompresi yang mengakibatkan COP $>1$. Dengan kata lain kondisi ideal siklus carnot tidak tercapai, pada penelitian ini terbukti bahwa tidak mencapai COP ideal dan bernilai lebih besar dari 1 .

\section{Efisiensi Mesin Pendingin}

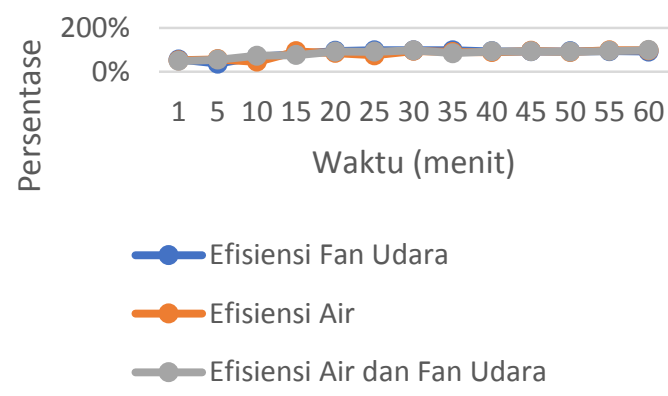

Gambar 6. Efisiensi Mesin Pendingin

Pada variabel pertama yaitu mesin pendingin dengan media pendingin fan didapatkan nilai rata-rata COP actual sebesar 5,3. Dan menghasilkan kinerja efisiensi terbaik pada menit ke-25 sampai menit ke-35 yaitu dengan efisiensi $97 \%$. Lalu di variabel kedua yaitu mesin pendingin dengan media pendingin air didapatkan nilai rata-rata COP aktual sebesar 4,0. Lalu menghasilkan kinerja efisiensi terbaik pada menit ke-55 sampai menit ke-60 yaitu dengan efisiensi $97 \%$. Dan yang terakhir adalah variabel mesin pendingin dengan media pendingin konfigurasi air dan fan udara didapatkan nilai rata-rata COP actual sebesar 4,4. Dan menghasilkan kinerja efisiensi terbaik pada menit ke-60 yaitu dengan efisiensi $98 \%$.

Dari data hasil tersebut dapat disimpulkan bahwa kondisi aktual mesin pendingin dengan media pendingin normal tidak dapat dapat mencapai kondisi ideal sesungguhnya hal tersebut dibuktikan dengan kinerja maksimal efisiensi hanya berada di angka $97 \%$. Sementara itu mesin pendingin dengan media pendingin air dapat bekerja melebihi kondisi aktual mesin pendingin yaitu melebihi $100 \%$ yang dianggap sebagai kondisi ideal suatu mesin pendingin. Kinerja maksimal media pendingin air mencapai angka $97 \%$ yang sama dengan media pendingin fan udara.

Dan yang terakhir mesin pendingin dengan media konfigurasi pendingin air dan udara yang merupakan media terbaik jika dibandingkan dengan hanya menggunakan salah satu media air dan fan udara saja. Kinerja maksimal media pendingin air dan fan udara ini mencapai kinerja maksimal sebesar 98\%. Yang dapat diartikan sebagai media pendingin terbaik. Dengan kinerja yang melebihi kondisi ideal hal tersebut dapat meringankan kerja sistem, memperpanjang umur suatu mesin karena tidak mendapatkan kalor berlebih dan membuat performa mesin menjadi dingin dengan lebih cepat.

\section{KESIMPULAN}

1. Temperatur maksimal yang dapat dicapai pendinginan kondensor dalam perancangan sistem mesin pendingin dari menit $0-60$ :

a. 4,40C pada menit ke 10 untuk mesin pendingin dengan media pendingin fan udara.

b. $-6,90 \mathrm{C}$ pada menit ke-15 untuk mesin pendingin dengan media pendingin air.

c. $-12,70 \mathrm{C}$ pada menit ke-15 untuk mesin pendingin dengan media pendingin air dan fan udara.

2. Debit air yang mengalir sangat mempengaruhi pencapaian temperatur dan efisiensi terbaik, pada percobaan kali ini didapatkan hasil massa laju air yang mengalir tiap menit adalah $0,4603 \mathrm{~kg} / \mathrm{s}$ dan mampu mengabil kalor panas mencapai temperatur $32^{\circ} \mathrm{C}$ yang dapat digunakan untuk kebutuhan lainnya.

3. Efisiensi sistem untuk setiap variasi media pendingin adalah :

a. Untuk mesin pendingin dengan media pendingin fan udara saja didapatkan $97 \%$.

b. Untuk mesin pendingin dengan media pendingin air saja didapatkan sebesar $110 \%$.

c. Dan untuk mesin pendingin dengan media pendingin air dan fan udara didapatkan $157 \%$. 


\section{DAFTAR PUSTAKA}

[1] Jamil, Asep Ahmad N. 2012. Pembuatan Mesin Pendingin. Matematika dan IImu Pengetahuan Alam, Indonesia, Depok.

[2] Komang Metty Trisna, et al. 2010. Analisa Performansi Sistem Pendingin Ruangan dan Efisiensi Energi Listrik padaSistem Water Chiller dengan Penerapan Metode Cooled Energy Storage Jurnal IImiah Teknik Mesin 4:43-50.
[3] Ma'sum, Zuhdi dan Wahyu Diah Proborini. 2015. Optimasi Proses Destilasi Uap Essential Oil Jurnal Reka Buan 1.

[4] G.R., Perdana, et al. 2014. Pengaruh Penggunaan Water Cooled Condenser Terhadap Prestasi Kerja Mesin Pendingin Menggunakan Refrigeran Lpg (The Influence Of Use Of Water Cooled Condenser Towards Engine Coolant Performance Using Lpg Refrigerants). 